This item was submitted to Loughborough's Research Repository by the author.

Items in Figshare are protected by copyright, with all rights reserved, unless otherwise indicated.

\title{
Differences in comfort perception in relation to local and whole body skin
} wettedness

\section{PLEASE CITE THE PUBLISHED VERSION}

http://dx.doi.org/10.1007/s00421-009-0983-z

PUBLISHER

(C) Springer-Verlag

VERSION

AM (Accepted Manuscript)

LICENCE

CC BY-NC-ND 4.0

REPOSITORY RECORD

Fukazawa, Takako, and George Havenith. 2019. "Differences in Comfort Perception in Relation to Local and Whole Body Skin Wettedness". figshare. https://hdl.handle.net/2134/12480. 
This item was submitted to Loughborough's Institutional Repository (https://dspace.lboro.ac.uk/) by the author and is made available under the following Creative Commons Licence conditions.

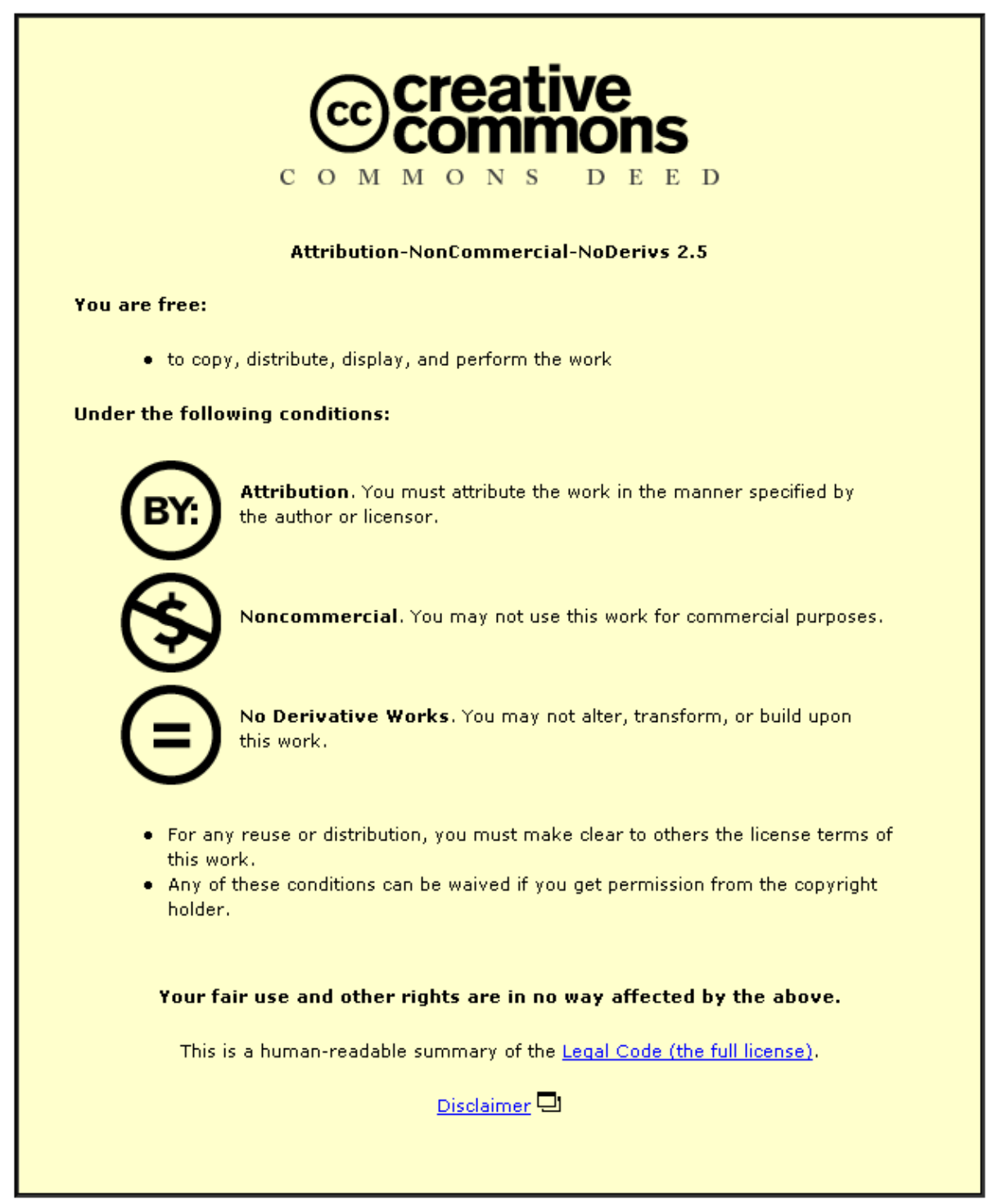

For the full text of this licence, please go to: http://creativecommons.org/licenses/by-nc-nd/2.5/ 
Editorial Manager(tm) for European Journal of Applied Physiology

Manuscript Draft

Manuscript Number:

Title: Differences in comfort perception in relation to local and whole body skin wettedness

Article Type: Original Articles

Keywords: Thermal comfort; Skin wettedness; Local thermal comfort limit; Evaporation

Corresponding Author: Dr. Takako Fukazawa, Ph. D.

Corresponding Author's Institution: Fukuoka Women's University

First Author: Takako Fukazawa, Dr.

Order of Authors: Takako Fukazawa, Dr.; George Havenith, Dr.

Abstract: Relevance of local skin wettedness (wlocal) to general thermal comfort while wearing clothing was investigated in eight males. In the experiments, skin wettedness of the whole body (wbody) was controlled to be around the thermal comfort limit, while wlocal in different target locations of equal area (anterior and dorsal torso, arms, and thighs) was pushed beyond the comfort limit using special test garments. Subjects walked on a treadmill at $4.5 \mathrm{~km} \cdot \mathrm{hr}-1$ under $22{ }^{\circ} \mathrm{C}$ $50 \% \mathrm{RH}$. Arms and thighs were thermally in discomfort when their wlocal exceeded 0.32. On the other hand, discomfort in the anterior and dorsal torso was initiated when their wlocal arrived at 0.42 and 0.45 . That is, the relation of the local comfort limit with wlocal differed depending upon the location. It was observed however, that general discomfort was not induced when wbody remained below 0.36 even if wlocal was higher than its local comfort limit.

Suggested Reviewers: Mark Richards Dr.

EMPA Material Science and Technology

mark.richards@empa.ch

$\mathrm{He}$ is one of expert in clothing physiology. 
Kalev Kuklane Dr.

Associate Professor, Dept of Design Sciences, Lund University

kalev.kuklane@design.lth.se

$\mathrm{He}$ is working on human thermal comfort and physiology in thermal environment.

Ingvar Holmér Dr.

Professor, Dept of Design Sciences, Lund University

ingvar.holmer@design.lth.se

$\mathrm{He}$ is a member of ISO TC159, SC5, and WG1.

Peter Broede Dr.

IfADo

broede@ifado.de

$\mathrm{He}$ is also one of experts in clothing physiology.

Opposed Reviewers: 
Dear Sirs:

Please find our paper entitled

"Differences in comfort perception in relation to local and whole body skin wettedness ".

We would be grateful if you would kindly review our paper for publication in European Journal of Applied Physiology.

Thank you for your kind consideration.

Best regards,

Takako Fukazawa, Ph. D. 


\section{Introduction}

Temperature sensation and thermal discomfort have a high correlation with skin surface temperature in cold environments. On the other hand, in warm environments or during exercise, thermal discomfort is more highly correlated to sweating than to the skin surface temperature, because the skin temperature is maintained at a favourable level due to evaporative cooling by the sweating. Winslow et al. [1939] suggested that one of the factors for this thermal discomfort was the level of wettedness over the skin surface, which is now widely known as an index $(w)$ for the skin wettedness [Gagge et al. 1937].

Gagge et al. [1969] found that a state of thermal comfort can be realised when the skin wettedness of the whole body remains below 0.3 . This value is called the thermal comfort limit of the whole body. Therefore, the skin wettedness can be recognised to be one of the most convenient indices to predict the thermal comfort level for humans on the warm side [Havenith et al. 2002b].

Some studies [e.g., Gonzalez et al. 1998] employed the relation between the thermal comfort sensation and the skin wettedness to improve work environments or clothing design for comfort and protection. They studied the relation through the condition in the trunk area due to its high sweat rate and large surface area in the whole body. On the other hand, recent reports [e.g., Toftum et al. 1998; Koshiba and Tamura 1995] have shown that thermal and humid sensitivities in the body depend upon the region. For instance, cold/warm thresholds in the trunk are higher than those in other area [Uchida and Tamura 2007] due to smaller numbers of cold/warm spots on the skin [e.g., Choi and Seol, 2001]. Results of these reports imply that the thermal comfort limit for wettedness of the body may also be different for individual locations. It could also be that, rather than comfort being related to the mean whole body $w\left(w_{b o d y}\right)$, it may be dominated by a single zone, most likely the wettest one ( $\left.w_{\text {local }}\right)$.

Furthermore, the production of sweat differs for different body regions [Havenith et al. 2008; Machada-Moreira et al. 2007]. This different production, combined with possible differences in regional evaporation induced by differing convection currents over different skin areas, will in itself lead to different wettedness distributions. As the latter is heavily influenced by clothing design (ventilation openings, wicking etc), knowledge of regional skin wettedness sensitivity is of the utmost importance in the design and optimisation of clothing.

Thus, in the present study, local thermal comfort limits were investigated through experiments on subject while manipulating the regional skin wettedness. The skin wettedness of the whole body was controlled to be maintained around the comfort limit of the whole body, while that of a selected target region of the body was kept higher than the limit in order to examine relevance of the local skin wettedness to whole body thermal comfort.

\section{Experimental design}

In this study, skin wettedness for both the whole and individual regions were simultaneously controlled at 
the desired level by means of a combination of custom made over-all garments, the exercise level and the environmental condition.

\section{Design of the test garment for the study}

Four regions in the body, front trunk (Front: chest and belly), back trunk (Back: back and buttock), arms (Arms: forearm and upper arm), and thighs (Thighs) were selected as target locations, all with similar surface areas as shown in Table 1.

In the experiment, the skin wettednesses in both the whole body and a target location was manipulated simultaneously by means of 5 types of test garments shown in Fig. 1; four of them were designed to increase the skin wettedness in a specific region above the comfort limit of the whole body, while the last one was for control.

All of the test garments were basically made of polyester fleece material with a high permeability for both air and water vapour (intrinsic local thermal resistance $=0.14 \mathrm{~m}^{2} \mathrm{~K} \cdot \mathrm{W}^{-1}$; intrinsic local water vapour resistance $=$ $554 \mathrm{~s} \cdot \mathrm{m}^{-1}$ hereafter, permeable). For the individual target location in the each test garment, however, the same fleece as used elsewhere was laminated externally with polytetrafluoroethylene (PTFE) membrane to reduce the local vapour permeability (intrinsic local thermal resistance $=0.15 \mathrm{~m}^{2} \mathrm{~K} \cdot \mathrm{W}^{-1}$; intrinsic local water vapour resistance $=1,056 \mathrm{~s} \cdot \mathrm{m}^{-1}$; hereafter, impermeable). The employed test garments provided an almost identical thermal resistance of about $0.14 \mathrm{~m}^{2} \mathrm{~K} \cdot \mathrm{W}^{-1}$, while they showed larger water vapour resistances in the individual target location than in the remaining parts.

\section{Experimental design for the study}

Although thermal comfort can be realised when the skin wettedness is kept below 0.3 , target mean skin wettedness in the whole body ( $w_{b o d y}$, henceforth) was selected as 0.4 in the experiment, as participants may not provide accurate information about thermal comfort sensations if they are in the near neutral state [Toftum et al., 1998]. In order to detect the change from comfort to discomfort with sufficient sensitivity, the experiment was designed to slowly raise $w_{\text {body }}$ over time, achieving a value of 0.4 by the end of the exposure. If loaded too lightly, discomfort may not occur. If loaded too heavily, the transition to discomfort may go too fast and not provide the information desired. In order to induce the desired $w_{b o d y}$ at around 0.4 , the subject must generate a specific level of energy, which is equivalent to 3 METs of metabolic heat production according to Nishi and Gagge [1977]. In the study, the desired $w_{b o d y}$ was attained by sweating through walking at $4.5 \mathrm{~km} \cdot \mathrm{hr}^{-1}$, equivalent to a heat production of 314 watts for the standard person [ISO 8996 1990].

Environmental conditions were decided upon based on the interaction between metabolism, air velocity [ISO 7730 1995], heat and water vapour transfer from the clothed body and thermal and water vapour resistances of clothing [Havenith 2002; Havenith et al. 2002; Nishi and Gagge 1970; Lotens 1993].

Humidity or stuffiness sensations are perceived when water vapour pressure at the skin exceeds a particular value ranging from $15 \mathrm{mmHg}$ to $22 \mathrm{mmHg}$ [e.g. Tamura and Koshiba 1995; Ushioda et al. 1995]. According 
to numerous papers dealing with clothing thermal comfort [e.g. Harada1996; Suzuki 1932], we can stay in neutral or comfort condition thermally when the microclimate is maintained at a condition of $32{ }^{\circ} \mathrm{C}$ with $50 \% \mathrm{RH}(=18 \mathrm{mmHg})$ under any external environmental conditions. Under these conditions, the mean skin temperature becomes $33{ }^{\circ} \mathrm{C}$. Thus, mean skin temperature during the experiments should be kept at around $33{ }^{\circ} \mathrm{C}$, because the thermal comfort cannot be accomplished if the mean skin temperature is above $35{ }^{\circ} \mathrm{C}$ [Mochida 1994].

To achieve the desired $w_{b o d y}$ (pilot studies), the environmental condition was regulated at $22{ }^{\circ} \mathrm{C}$ air and wall temperatures and $10 \mathrm{mmHg}$ in absolute water vapour pressure $(50.5 \% \mathrm{RH})$. Air velocities of, 0.1 and $0.2 \mathrm{~m} \cdot \mathrm{s}^{-1}$ were chosen at rest and during the exercise periods, respectively.

\section{Experiment}

\section{Subjects}

Eight healthy un-acclimatized Europeans male university students (age $22.4 \pm 4.2$ years, height $178.8 \pm$ $6.2 \mathrm{~cm}$, weight $74.7 \pm 8.8 \mathrm{~kg}$, and BMI $23.4 \pm 2.7 \mathrm{~kg} \cdot \mathrm{m}^{-2}$ ) served as test volunteers in the experiment. All subjects were given full information about the purpose, procedure, and risks prior to the experiment. They all expressed an understanding of the experiments by signing a statement of informed consent.

\section{Procedure and Measurements}

The experiments were conducted in a climate chamber for $65 \mathrm{~min}$ in total, in which air and wall temperatures, relative humidity, and air velocity were maintained at the targeted conditions. In the first 15 min, the subject rested and then they started the exercise of walking on a treadmill (Tunturi, T-treck-gamma-300, Finland) till the end of the experiment. During the experiment, aural canal temperature was measured using a thermistor (Grant, UK) as core temperature. Eight skin temperatures (forehead, scapula, chest, upper arm, forearm, hand, thigh, and calf) were measured by Thermocouples (T-type, Omega, UK). A mean skin surface temperature was calculated from the obtained skin temperatures and the mean saturated water vapour pressure at the skin as well [Nishi and Gagge 1970; ISO 9886 2004]. Hygrometers (Sensirion, Switzerland) were placed on 4 locations of scapula, chest, upper arm, and thigh. These parameters were recorded in data loggers (Grant Squirrel, UK and MSR, Switzerland) continuously with an interval of $1 \mathrm{~min}$. A subjective questionnaire was also completed for the thermal comfort sensations of the whole body and the individual target location using a seven-point Likert scale (very comfortable to very uncomfortable).

Before the commencement of the first experiment, the subjects were instructed how to answer the psychological thermal sensations and how to fill the questionnaire. The subject arrived at the laboratory at least $30 \mathrm{~min}$ before starting the measurement. Upon arrival, the subject was equipped with the temperature sensors and the hygrometers. After the application of all instrumentation, the subject dressed in the test clothing, and socks and shoes and was then weighed, fully clothed, by an electronic balance (Sartorius, 
Germany, $150 \mathrm{~kg}$; resolution 1g).

\section{Skin wettedness}

Skin wettedness $(w$, dimensionless) is defined as

$$
w=\frac{q_{s w}}{q_{e \max }}+0.06
$$

where $q_{s w}$ is the evaporated heat flux from the clothed body caused by regulatory sweating $\left(\mathrm{W} \cdot \mathrm{m}^{-2}\right), q_{e m a x}$ the maximal evaporative heat flux from the body with the actual clothing and skin surface temperatures for a totally wet skin $\left(\mathrm{W} \cdot \mathrm{m}^{-2}\right)$, and 0.06 the minimal skin wettedness by skin diffusion (dimensionless). The rate of $q_{\text {emax }}$ can be obtained by the following equation:

$$
q_{e \max }=\frac{C_{s k, s}-C_{e}}{R_{D}} \cdot L
$$

where $C_{s k, s}$ is the saturated water vapour concentration of the skin surface $\left(\mathrm{kg} \cdot \mathrm{m}^{-3}\right), C_{e}$ the water vapour concentration of the environment $\left(\mathrm{kg} \cdot \mathrm{m}^{-3}\right), R_{D}$ the over-all water vapour resistance from the skin surface to the environment $\left(\mathrm{s} \cdot \mathrm{m}^{-1}\right), \mathrm{L}$ the latent heat coefficient $\left(2,430 \mathrm{~kJ} \cdot \mathrm{kg}^{-1}\right)$. The actual evaporated heat flux from the body with the clothing, $q_{s k}$, can be obtained by:

$$
q_{s k}=\frac{C_{s k}-C_{e}}{R_{D}} \cdot L
$$

where $C_{s k}$ is the water vapour concentration of the skin surface $\left(\mathrm{kg} \cdot \mathrm{m}^{-3}\right)$. In Eq. 3, $q_{s k}$ consists of the evaporated heat fluxes by the regulatory sweat and by the skin diffusion. Accordingly, it can be also expressed as

$$
q_{s k}=q_{s w}+q_{\text {diff }},
$$

where $q_{\text {diff }}$ is the evaporated heat flux by the skin diffusion $\left(\mathrm{W} \cdot \mathrm{m}^{-2}\right)$. This $q_{\text {diff }}$ can be obtained using Eq. 1 as

$$
q_{\text {diff }}=0.06 \cdot q_{\text {emax }} \text {. }
$$

Thus, from Eqs. 1, 3, 4, and 5, we can obtain the following equation for calculating the skin wettedness simply using $C_{s k}, C_{s k, s}$ and $C_{e}$

$$
w=\frac{q_{s k}}{q_{e \max }}=\frac{C_{s k}-C_{e}}{C_{s k, s}-C_{e}} .
$$

\section{Statistics}

In the present study, the primary independent variable is the test garment (5 levels), or in other words, the individual target location. Dependent variables are aural canal and skin surface temperatures, skin wettedness, and thermal comfort sensations. These measured data over time are analysed by a two-way analysis of variance with repeated-measures (ANOVA) using the data taken every $5 \mathrm{~min}$. The effect of the $w_{\text {local }}$ upon thermal comfort of the whole body is rated by means of one-way ANOVA. In all analyses, $p<0.05$ is used to 
establish a significant difference. Regression analysis is performed to assess the correlations among thermal comfort sensations, the aural canal temperature, and the skin wettedness. Data in figures and tables are given in terms of the mean values and their standard deviation (SD).

\section{Results}

\section{Confirmation of the obtained data}

Figure 2 shows the variation of the skin wettedness of the whole body $\left(w_{b o d y}\right)$ over time. A main effect of time is observed $(p<0.001)$. However, no significant difference in $w_{b o d y}$ between garments is observed ( $p=$ 0.50 ), indicating that $w_{b o d y}$ was successfully kept at a similar level during the whole period of the experiment for all test garments. In the experiment, $w_{\text {body }}$ stayed around 0.15 during the rest period. Then $w_{b o d y}$ gradually increased from about $10 \mathrm{~min}$ after starting the exercise, rising to $0.38-0.40$ at end of the experiment. Table 2 shows the obtained experimental data of temperature, water vapour concentration, wettedness of the skin surface in the individual target locations during the first and the last $15 \mathrm{~min}$. Results of one-way ANOVA indicate that in all the locations, both the initial and the last $w$ 's in the individual target location show significantly higher values than the other zones because of the significantly high water vapour concentration of the skin due to the impermeable fabric. In general, there is, however, no difference in the skin surface temperature in the individual target location.

Figure 3 indicates the $w$ 's in the 4 target locations during wearing the test garments of Types $\mathrm{A}$ to $\mathrm{D}$ for the last $15 \mathrm{~min}$ in the experiment. Results of the one-way ANOVA for $w$ on the individual target locations in different test garments show that $w_{\text {local }}$ for the target locations was always significantly higher when that area was covered with the low permeability fabric than for the all the other garments: Front trunk, garment of Type A: $(p<0.001)$; Back trunk, Type B: $(p<0.001)$; Arms, Type C: $(p<0.01)$ and Thighs, Type D: $(p<$ $0.001)$.

Thus, we confirmed that the w's in both the whole body and the target locations were maintained simultaneously at the aimed levels (equal for $w_{\text {body }}$, and raised $w_{\text {local }}$ for targeted area) according to the results mentioned above.

\section{Thermal comfort sensation in the whole body}

In Fig. $4, w_{b o d y}$ is plotted against thermal comfort sensation. This figure includes all the data from the whole period of the experiment and shows the mean values of every 5 min for each test garment. The thermal comfort of the whole body is in inverse proportion to the $w_{b o d y}$ for all the tested garments. A high, significant, correlation is found between the thermal comfort sensation and $w_{b o d y}(\mathrm{r}=0.92 ; p<0.001)$. Based on these data, the thermal comfort limit for the whole body in the experimental conditions is found to be 0.36 (SD $0.05)$ in terms of the $w_{b o d y}$. The thermal comfort sensation for the whole body can be given by Thermal comfort sensation $=-7.30 \cdot w_{\text {body }}+2.60$ 


\section{Local thermal comfort sensation}

The local thermal comfort sensations in the 4 target locations are illustrated as a function of their $w_{\text {local }}$ 's in Figs. 5-1 to 5-4. The plotted data are results obtained on all the 5 test garments during the whole period of the experiment. The individual local thermal comfort decreases with the increasing $w_{\text {local }}$ and is inversely proportional to the $w_{\text {local }}$ expressed by their regression lines.

(a) Front Local thermal comfort sensation $=-5.15 \cdot w_{\text {Front }}+2.06$

(a) Back Local thermal comfort sensation $=-3.88 \cdot w_{\text {Back }}+1.75$

(a) Arms Local thermal comfort sensation $=-7.73 \cdot w_{\text {Arms }}+2.47$

(a) Thighs Local thermal comfort sensation $=-6.48 \cdot w_{\text {Thighs }}+2.08$

Their correlation coefficients are found to be higher than 0.7 with a high significance of $p<0.001$ in all the 4 target locations.

\section{Correlation among comfort sensation, temperature, and wettedness of the skin surface}

Results of correlation analysis between the thermal comfort sensation in the whole body and temperature and wettedness of the skin surface are summarised in Table 3. Significant correlations have been observed between comfort sensation of the whole body and wettednesses of the four target locations, though these correlations are lower. Correlations of the comfort sensation with the local skin surface temperatures are only significant for the Back and Arms, not for the Front and Thighs.

Table 4 presents correlation coefficients of local comfort sensation and local skin surface temperatures and local wettedness in the individual target location. Correlations of the local thermal comfort are found to be significant with both the local skin temperature and wettedness in the Back and Arms. For the Front and Back only the correlation of the local comfort with the local skin wettedness was significant, the correlation with skin temperature was not.

\section{Discussion}

\section{Correlation of the thermal comfort and the skin wettedness}

When we are in warm environments or during exercise, thermal comfort sensation is more strongly related to the level of skin wettedness than to the temperature of the skin surface [Winslow et al., 1939]. In the present study indeed, the obtained results indicate that the whole body thermal comfort sensation is mainly caused by the skin wettedness. This conclusion can be deduced from Tables 3 and 4. That is, in Tables 3 and 4, absolute values of the correlation coefficients of thermal comfort with skin wettedness $(w)$ are larger than those with the skin surface temperature both for the whole body and for the target locations, except for the Arms. Accordingly, the thermal comfort sensation depends mainly upon the $w$ in the present experimental conditions. 


\section{Relevance of local skin wettedness to thermal comfort in the whole body}

According to the obtained results and the derived Eq. 7, the thermal comfort limit of the whole body is found to be 0.36 (SD 0.05 ) in terms of $w_{\text {body }}$. This comfort limit is slightly higher than often quoted value of $0.25-0.3$ [Gagge et al. 1969; Takanokura 1997] but is still close to the usual range. (This reason will be discussed later). It is important to note that this comfort limit for the whole body is obtained under conditions, in which $w_{\text {local }}$ in the target different locations is considerably higher than in the rest of the body. This indicates that the local thermal comfort does not influence significantly the general thermal comfort within the present experimental condition (see Fig. 2).

In the present study, the thermal comfort limit for the whole body was found to be 0.36 in terms of $w_{b o d y}$. Gagge et al. [1969] reported that the general thermal comfort state was maintained when the $w_{b o d y}$ was less than $0.25-0.3$ through their experiment using subjects without clothing at rest. Takanokura [1997] performed a series of experiments with clothed young females to examine influence of water vapour adsorbability of clothing upon the thermal comfort sensation. In her study, the subjects at rest were kept in thermally comfort state till $w_{\text {body }}$ reached $0.25-0.3$. These reported values of the thermal comfort limit are smaller than the ones obtained in the present study. However, Nishi and Gagge [1977] have found that the thermal comfort limit depends upon metabolism due to exercise e.g.; the comfort limit increases with the increasing metabolic heat production. In case the body produced heat energy of 1 Met, comfort was if $w_{b o d y}$ was less than 0.22 , but the comfort limits for 2 and 3 Mets were observed to be 0.29 and 0.36 , respectively. In the present study, the employed exercise condition was $4.5 \mathrm{~km} \cdot \mathrm{hr}^{-1}$ walking, equivalent to a metabolic heat production of 3 Mets [ISO 8996 1990]. Thus, the observed thermal comfort limit in the present study of 0.36 shows excellent agreement with the prediction given by Nishi and Gagge [1977] and the differences with earlier studies can be attributed to the difference in the metabolism [Gagge et al. 1969; Takanokura 1997].

In the present study, head as well as face and hands were exposed to the environment. Those regions remained in a comfortable state during the whole period of the experiment. This may be one of the reasons why the thermal comfort state of the whole body was not affected by the local thermal comfort sensation of the target zones, because head, face, and hands are predominant regions for the general thermal comfort as reported by Zhang et al. [2004]. According to Boutcher et al. [1995] and Kato et al. [2001], face and head are so sensitive against the thermal stimulus that the thermal sensation in the whole body is effectively dominated by their local thermal sensations. They have shown that the body in warm discomfort can be changed to comfort condition when face and head were given a cooling treatment. Mori et al. [2004] found experimentally and theoretically that the increased core temperature dropped when a cooling treatment was given to the head. Okada and Fukai [2003] demonstrated that a treatment of cooling/warming for hands brings the body into thermal comfort, while the core temperature stays higher/lower than the appropriate level. Accordingly we can conclude that, in case when the effective parts such as head, face, and hands on 
the thermal comfort sensation are kept in comfort state, the thermal comfort in the whole body does not depend upon $w_{\text {local }}$, but links to $w$ of the clothed areas within the limits of this study $\left(w_{\text {body }}<0.4\right)$.

\section{Local thermal comfort limit and local thermal comfort sensitivity}

It is found in Fig. 5 that each correlation coefficient is so high that the obtained individual correlation line is reliable and thus it is useful to discuss the relation between the $w_{\text {local }}$ and that area's thermal comfort sensation. Slopes of the regression lines in the 4 target locations are shown in Fig. 6, which indicates the rate of change in the thermal comfort due to the increase in the $w_{\text {local }}$. In other words, this slope represents 'thermal comfort sensitivity'. According to the comparison of the local thermal comfort sensitivity among the target locations, it is found that the slope of the Front is remarkably gentler than that of the Arms, while it is steeper than that of the Back. The thermal comfort sensitivity of the Back is significantly lower than that of the Arms (all $p<0.05$ ). No significant difference is found between the Thighs and the other locations because of the large SD, though the difference between Thighs and Front approaches significance $(p=0.052)$. In addition, there is a tendency in thermal comfort sensitivity of Thighs to be different from those of the Back and Arms (both $p=0.19$ ). The general picture is that of a higher sensitivity in the periphery compared to the torso.

The thermal comfort limits can be obtained for the individual target location using the regression lines from Figs. 5-1 to 5-4, as statistical significances have been confirmed in the thermal comfort sensitivity as shown in Fig. 6. According to these regression lines, the subjects sensed their skin surface humidity as negative in the Arms and the Thighs around $w_{\text {local }}=0.32$. On the other hand, comfort limits in the Front and the Back are 0.40 and 0.45 , respectively.

The comfort limits in the Arms and the Thighs are thus lower than those in the Front and the Back, consistent with a higher sensitivity, and consistent with Toftum et al.'s data [1998]. Following a different technique, they have reported that perception of arms against humidity is more sensitive than those of chest and back. It can be inferred through the present study that the local thermal comfort sensitivity has a great deal of relevance to the humidity sensation because the $w$ becomes a predominant factor in the thermal comfort under warm environments or during exercise. This fact was firstly pointed out qualitatively by Winslow et al. [1939] 70 years ago. The present study confirmed this tendency based on the quantitative statistical treatment for the individual locations.

\section{Relation between the evaporative heat flux and thermal comfort sensation}

In order to discuss the influence of magnitude of the released evaporated heat flux from the skin surface $\left(q_{s k}\right)$ upon the thermal comfort sensation, $q_{s k}$ from the individual location within the test garments of type A to $\mathrm{D}$ were calculated employing Eq. 3. The water vapour resistance $R_{D}$ in the equation was determined on a thermal manikin (Measurement Technology Northwest, USA, Newton). According to the manikin 
measurement, the water vapour resistances of the permeable and the impermeable zones in the test garment were obtained as 691 and $1,192 \mathrm{~s} \cdot \mathrm{m}^{-1}$, respectively.

Figs. 7-1 to 7-4 show the calculated $q_{s k}$ from the body surface in the individual location. No difference is observed in $q_{s k}$ for a specific location caused by the suits. It seems that transferred mass fluxes are almost unchanged by the difference in resistance. Considering Eq. 3, it is thus obvious that the increased resistance of the impermeable fabrics is fully compensated for by an increased vapour pressure at the skin, compared to the permeable fabric condition. On the other hand, magnitude of $q_{\text {emax }}$, which can be calculated through Eq. 2, is considerably different in the individual target locations. In the target location of Front, the $q_{\text {emax }}$ in type A indicates a steady rate of 52 to $57 \mathrm{~W} \cdot \mathrm{m}^{-2}$ for the whole test period, while those in types B to D show a larger rate of 76 to $94 \mathrm{~W} \cdot \mathrm{m}^{-2}$. Therefore, in the present study, the magnitude of the $q_{\text {emax }}$ directly dominates the level of the skin wettedness, as no difference is found in the skin surface temperature (see Table 2) and $q_{s k}$ for each location. It should be noted that there is a limit to the compensation of higher vapour resistance by increased vapour pressure at the skin. These areas' vapour pressure will reach saturation earlier than in the case of permeable clothing, and once that happens $q_{s k}$ will fall behind for the impermeable fabric area.

It is of practical importance to improve clothing design for comfort and protection in terms of the heat and water vapour transfer through the clothing. In order to maintain the human body totally in thermal comfort under warm conditions and during exercise, $q_{\text {emax }}$ must be kept at a high level especially in extremities such as arms and thighs.

\section{Conclusion}

Local thermal comfort limits for local skin wettedness differ between different skin locations of the body. Sensitivity of thermal comfort sensation to skin wettedness is more sensitive in extremities than on the trunk. The thermal comfort of the whole body however, is not so much influenced by that of individual locations in the present experimental conditions. Although locally thermal discomfort is sensed based on local skin wettedness, the thermal comfort limit of the whole body is found to be 0.36 in terms of the whole body skin wettedness, independent of the location where skin wettedness was raised above normal. That is; the whole body can remain in thermally comfortable condition even when the local skin wettedness stays higher than the comfort limit.

\section{Acknowledgments}

We would express our sincere thanks to our subjects for their time and effort and to W.L. Gore Germany for their helpful technical support. The first author T. Fukazawa gratefully acknowledges research grants from Grand-in-Aid for PD research fellow (14-11488) of the Japanese Society for the Promotion of Science (JSPS) and Grand-in-Aid for Young Scientists (B) (18700573) of the Ministry of Education, Culture, Sports, Science and Technology-Japan (MEXT), which enabled us to conduct this study. We would like to thank Prof. 
Dr. Yutaka Tochihara for his support.

\section{References}

- Boutcher S H, Maw G J, Taylor N A S (1995) Forehead skin temperature and thermal sensation during exercise in cool and thermoneutral environments. Aviat Space Environ Med 66: 1058-1062

- Choi J, Seol H (2001) Distributions of skin thermoreceptors and clothing weights of Korean urbanites and farmers. J Physiol Anthropol 20: 375-377

- Gagge A P (1937) A new physiological variable associated with sensible and insensible perspiration. Am J Physiol 120: 227-287

- Gagge A P, Stolwijk J A J, Nishi Y (1969) The prediction of thermal comfort when thermal equilibrium is maintained by sweating. ASHRAE Trans. 75: Part II 108-122

- Gonzalez R R, Endrusick T L, Levell C A (1998) Biophysical properties and skin wettedness of garments wit variable moisture vapor transmission rate (MVTR). J Therm Biol 23: 41-48

- Harada R (1996) Kigokochi to kagaku (no English title). Shokabo Publishing Co., Ltd., Tokyo

- Havenith G (2002) The interaction between clothing insulation and thermoregulation; Exogenous Dermatology 1: 221-230

- Havenith G, Holmér I, Parsons K (2002) Personal factors in thermal comfort assessment: clothing properties and metabolic heat production. Energy and Buildings 34: 581-591

- Havenith G, Fogarty A, Bartlett R, Smith J C, Ventenat V (2008) Male and Female Upper Body Sweat Distribution during Running Measured With Technical Absorbents. Eur J Appl Physiol doi: 10.1007/s00421-007-0636-Z

- ISO 7730 (1995) Moderate thermal environments - Determination of the PMV and PPD indices and specification of the conditions for thermal comfort. ISO, Geneva

- ISO 8996 (1990) Ergonomics - Determination of metabolic heat production. ISO, Geneva

- ISO 9886 (2004) Ergonomics - Evaluation of thermal strain by physiological measurements. ISO, Geneva

- Kato M, Sugenoya J, Matsumoto T, Nishiyama T, Nishimura N, Okagawa T, Yonezawa H (2001) The effects of facial fanning on thermal comfort sensation during hyperthermia. Pflügers Arch 443: 175-179

- Koshiba K, Tamura T (1995) Factors Governing the Wet Sensations of Human skin. Journal of the Japan Research Association For Textile End-Use 36: 119-124 (in Japanese with English abstract)

- Lotens W A (1993) Heat transfer from humans wearing clothing. Ph. D. Thesis, Delft University of Technology, Delft

- Mochida T (1994) Lines of Constant Skin Temperature with Varying Skin Wettedness. ASHRAE Transactions 100: 222-229 
- Machado-Moreira C A, Smith F M, van den Heuvel A M J, Mekjavic I B, Taylor N A S (2007) Sweat secretion from the torso during passively-induce and exercise-related hyperthermia. Eur J Appl Physiol doi: 10.1007/s00421-007-0646-x

- Mori I, Hokoi S, Takada S (2004) Physiological responses to partial cooling in a warm environment -Numerical analysis and subject experiment-. Japanese Journal of Biometeorology 41: 19-30

- Nishi Y, Gagge A P (1970) Moisture Permeation of Clothing - A Factor Governing Thermal Equilibrium and Comfort. ASHRAE Transactions 76: 137-145

- Nishi Y, Gagge A P (1977) Effective temperature scale for use in hypo- and hyperbaric environments. Aviat Space Environ Med 48: 97-107

- Okada J, Fukai K (2003) Effects of Immersing One Hand in Warm Water on Skin Temperature. Thermal Sensation and Comfort. Kawasaki Medical Welfare Journal 13: 317-323

- Takanokura M (1997) Effect of change in wettedness on wear comfort during exercise with sweating. Bulletin of Showagakuin Junior College 33: 63-72

- Tamura T, Koshiba T (1995) Humidity Sensation of Human Body Part I General Humidity Sensation. Journal of the Japan Research Association For Textile End-Use, 36: 125-131 (in Japanese with English abstract)

- Toftum J, Jørgensen A S, Fanger P O (1998) Upper limits for indoor air humidity to avoid uncomfortably humid skin. Energy and Buildings 28: 1-13

- Ushioda H, Aoki A, Nakajima T (1995) Murekankaku no Hyokainshi (no English title). Journal of the Japan Research Association For Textile End-Use 36: 162-164 (in Japanese)

- Uchida Y, Tamura T (2007) Regional difference of thermal sensitivity on the skin surface of elderly. Journal of Home Economics of Japan 58: 579-587

- Suzuki H (1932) Ifukukikou no Kenkyu (no English title). Kokumin Eisei (present name in English: Journal of the Japanese Society for Hygiene) 9: 175-211 (in Japanese)

- Winslow C E A, Herrington L P, Gagge A P (1939) Physiological reactions and sensations of pleasantness under varying atmospheric conditions. ASHVE Transactions. 44: 179-194

- Zhang H, Huszenga C, Wang C (2004) Thermal sensation and comfort in transient non-uniform thermal environments. Eur J Appl Physiol 92: 728-733 


\section{Legends}

Figure 1 Five types of the employed over-all garment. The garments consist of combinations of permeable and impermeable fleece (polyester) for water vapour.

Figure 2 Development of mean weighted skin wettedness for the whole body $\left(w_{b o d y}\right)$ during the whole test period. According to one-way ANOVA analysis, a main effect of time is found to be significant, while that of the test garment is found to be not significant. Therefore, $w_{\text {body }}$ in all the test garments showed similar values every 5 min during the whole period of the experiment.

Figure 3 Mean resultant skin wettedness for the last 15 minutes of the testing in the target locations while wearing the 5 types of test garments. Asterisk indicates significant difference in $w_{\text {local }}$ on the individual target locations according to the one-way ANOVA. **: $p<0.01$ and ${ }^{* * *}: p<0.001$.

Figure 4 Relation between the thermal comfort sensation and the skin wettedness in the whole body, $w_{b o d y}$. There is a high significant correlation between the thermal comfort sensation and $w_{b o d y}$ in all the target locations.

Figure 5 Local thermal comfort limits in the 4 target locations of Front (5-1), Back (5-2), Arms (5-3), and Thigh (5-4) in relation to skin wettedness. A high correlation is seen between the local thermal comfort and the $w_{\text {local }}$ in the each target location.

Figure 6 Thermal comfort sensitivity in terms of the skin wettedness for the four target locations. Asterisk indicates significant difference in the thermal comfort sensitivity on the individual target locations. $*: p<0.05$.

Figure 7 Calculated local evaporative heat loss from the target locations wearing the test garments of type A to D. 


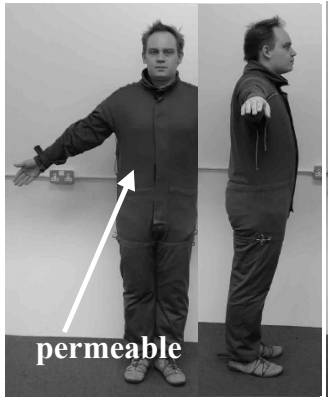

Control

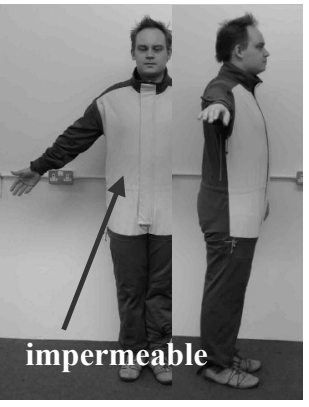

Type A

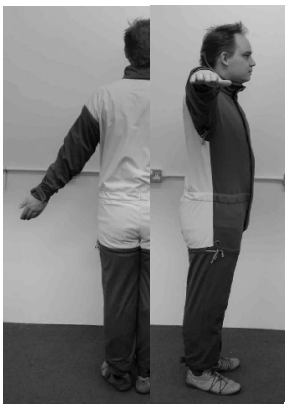

Type B

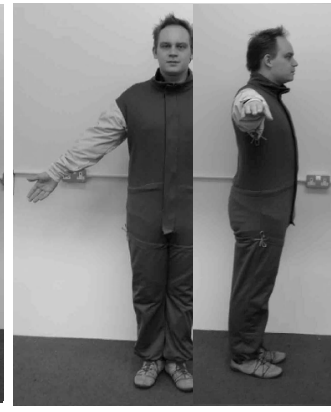

Type C

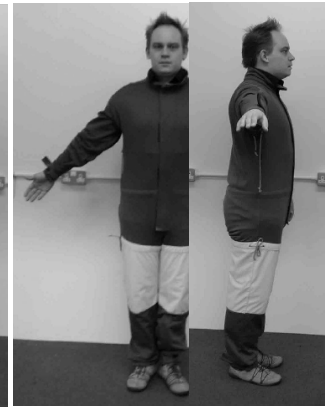

Type D

Figure 1 Five types of the employed over-all garment. The garments consist of combinations of permeable and impermeable fleeces (polyester) for water vapour. 


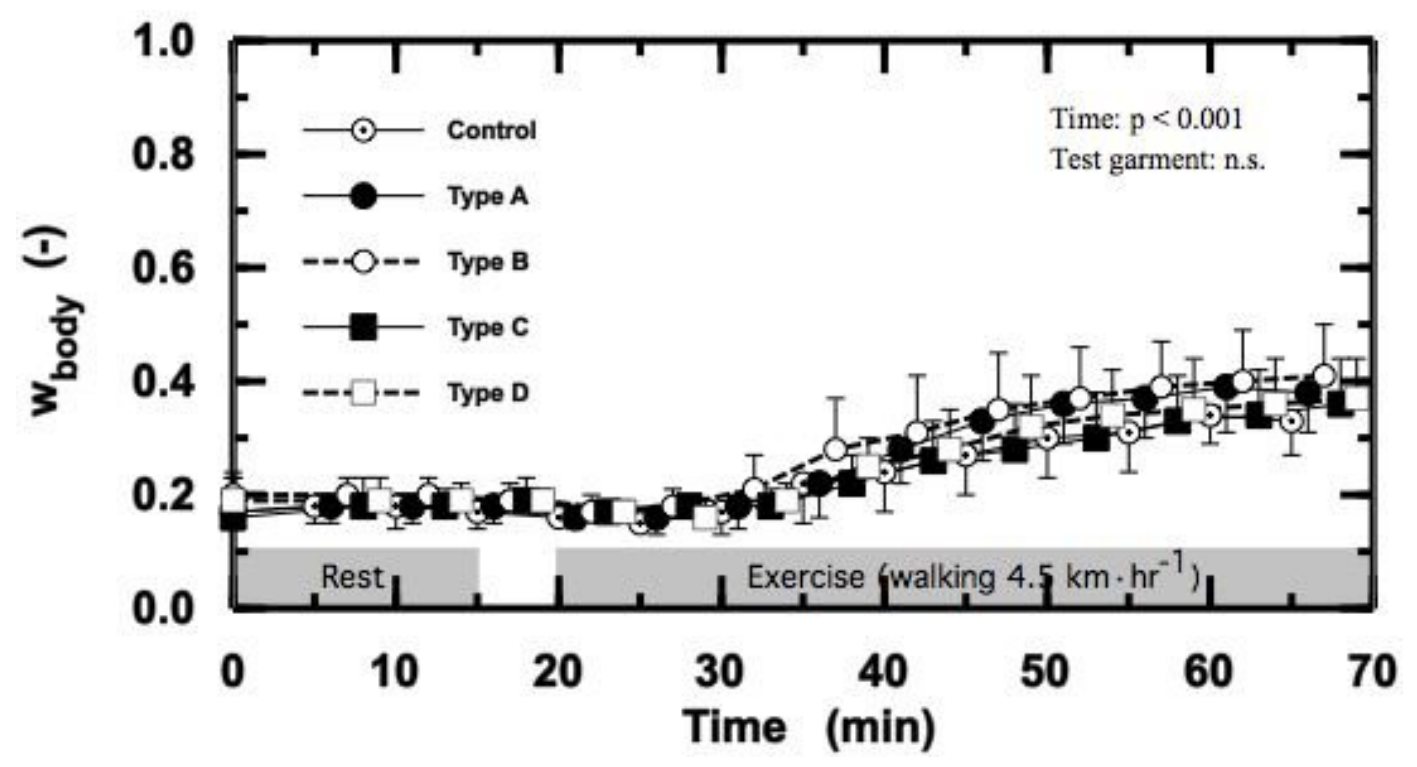

Figure 2 Development of mean weighted skin wettedness for the whole body $\left(w_{b o d y}\right)$ during the whole test period. According to one-way ANOVA analysis, a main effect of time is found to be significant, while that of the test garment is found to be not significant. Therefore, $w_{b o d y}$ in all the test garments showed similar values every 5 min during the whole period of the experiment. 


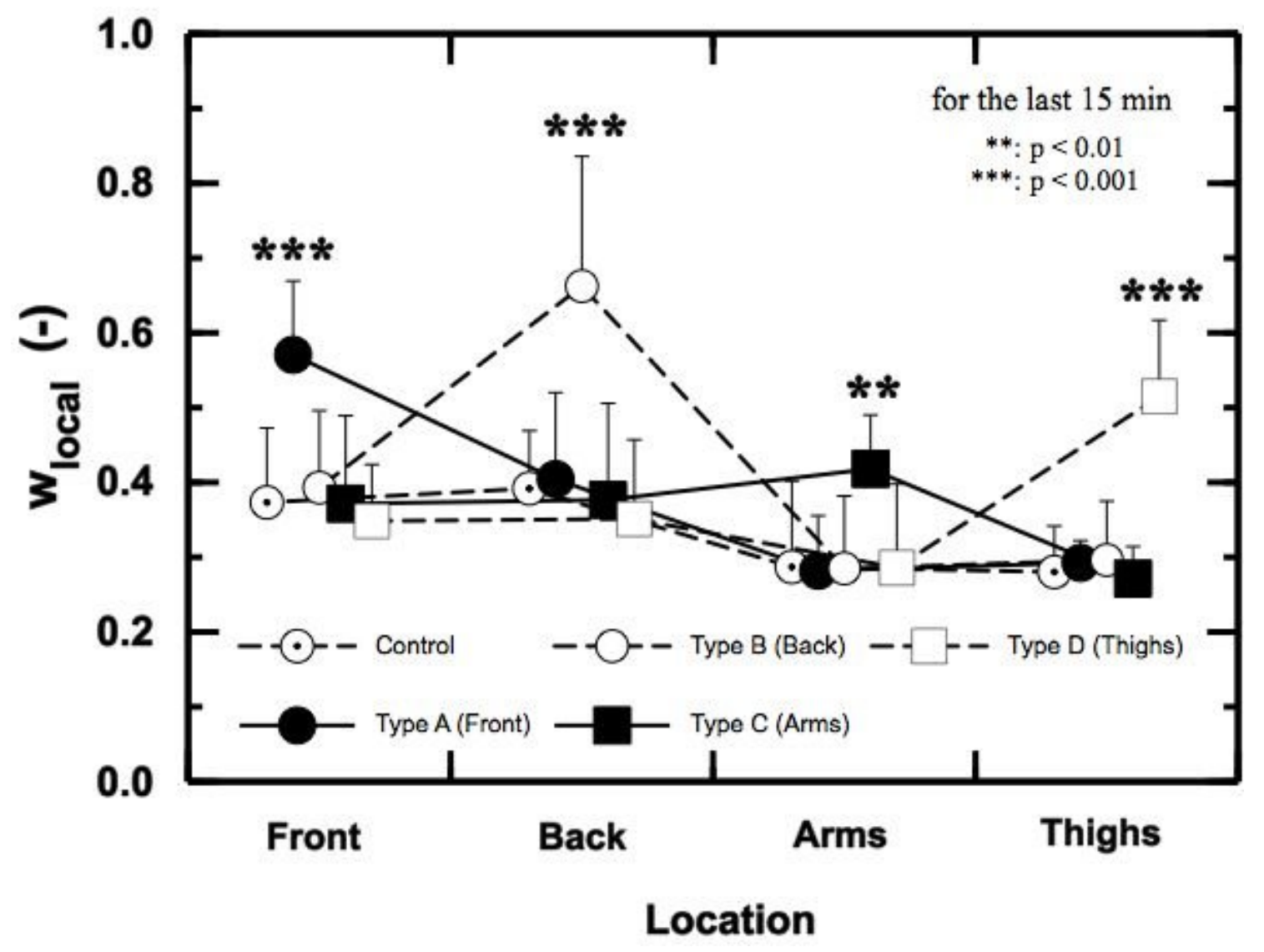

Figure 3 Mean resultant skin wettedness for the last 15 minutes of the testing in the target locations while wearing the 5 types of test garments. Asterisk indicates significant difference in $w_{\text {local }}$ on the individual target locations according to the one-way ANOVA. ${ }^{* *}: p<0.01$ and ${ }^{* * *}: p<0.001$. 


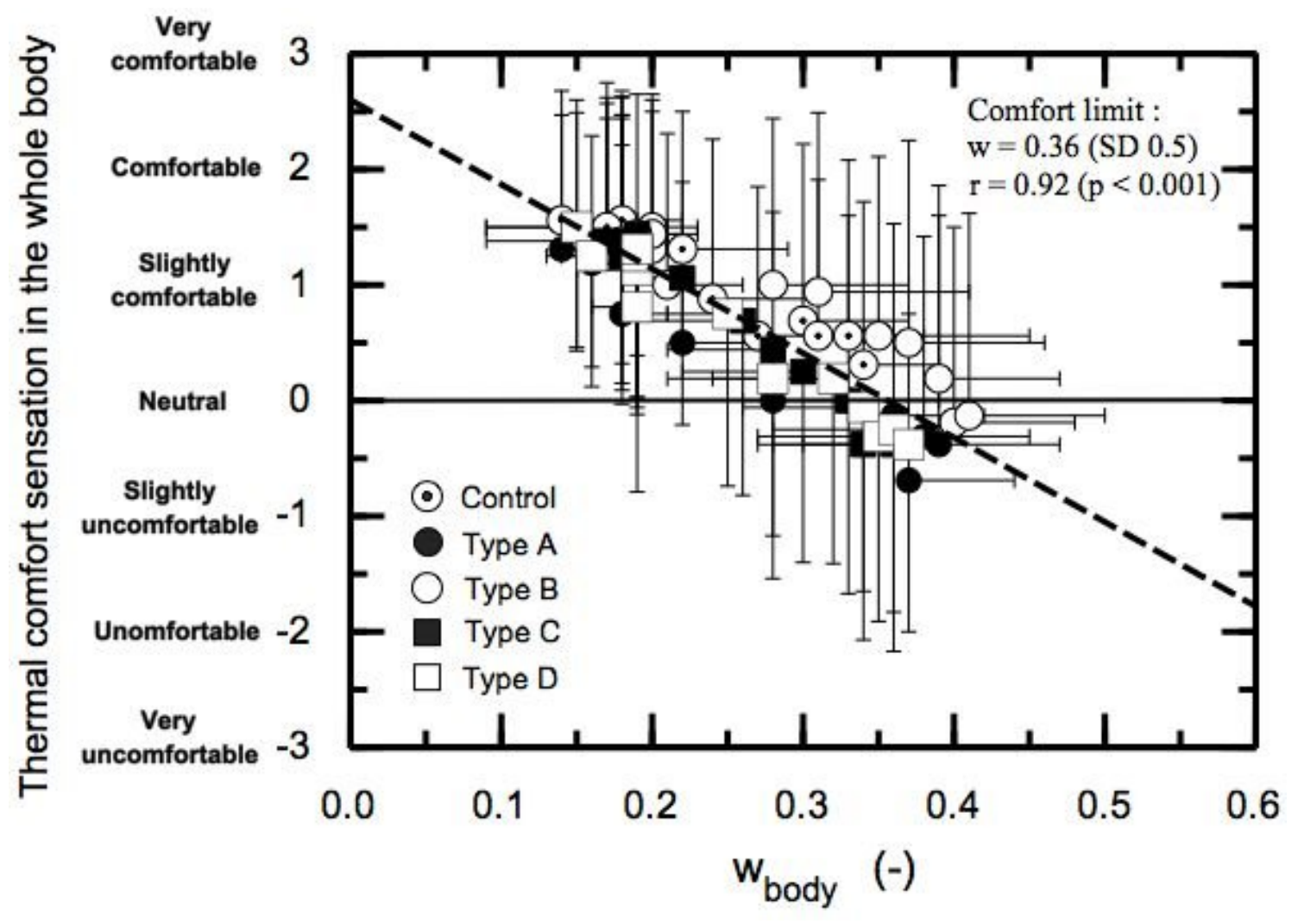

Figure 4 Relation between the thermal comfort sensation and the skin wettedness in the whole body, $w_{b o d y}$. There is a high significant correlation between the thermal comfort sensation and $w_{b o d y}$ in all the target locations. 


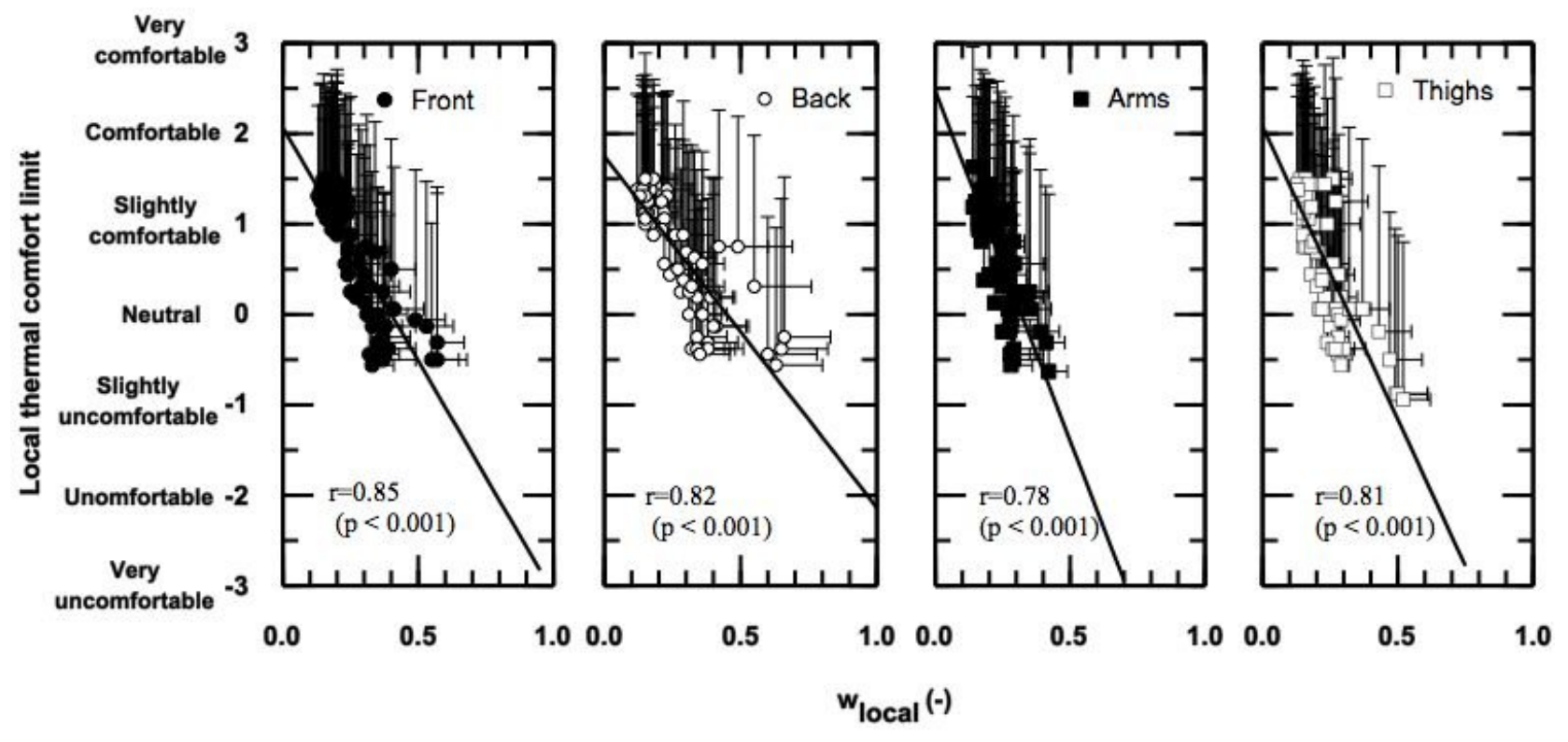

Figure 5 Local thermal comfort limits in the 4 target locations of Front (5-1), Back (5-2), Arms (5-3), and Thigh (5-4) in relation to skin wettedness. A high correlation is seen between the local thermal comfort and the $w_{\text {local }}$ in the each target location. 


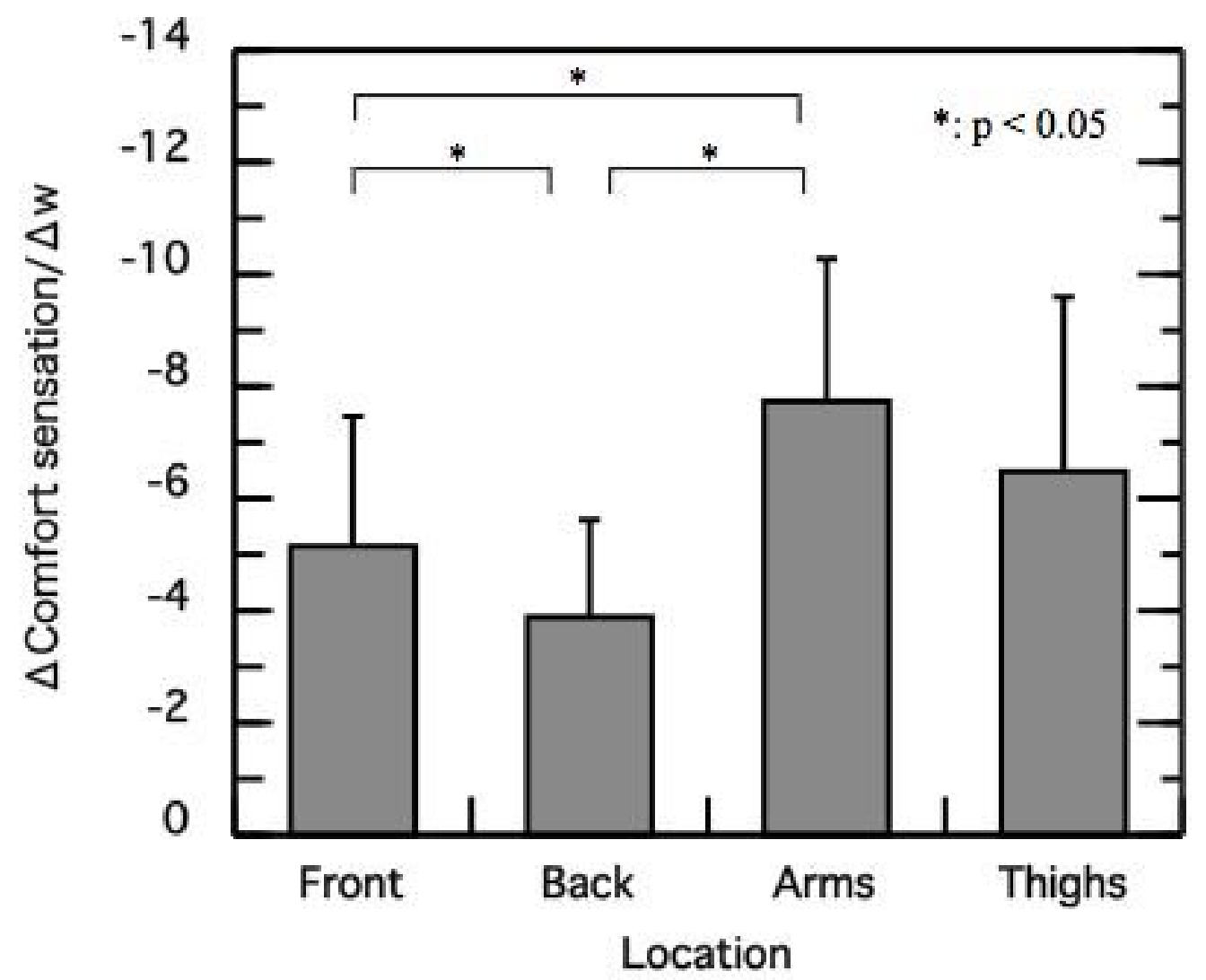

Figure 6 Thermal comfort sensitivity in terms of the skin wettedness for the four target locations. Asterisk indicates significant difference in the thermal comfort sensitivity on the individual target locations. *: $p<0.05$. 

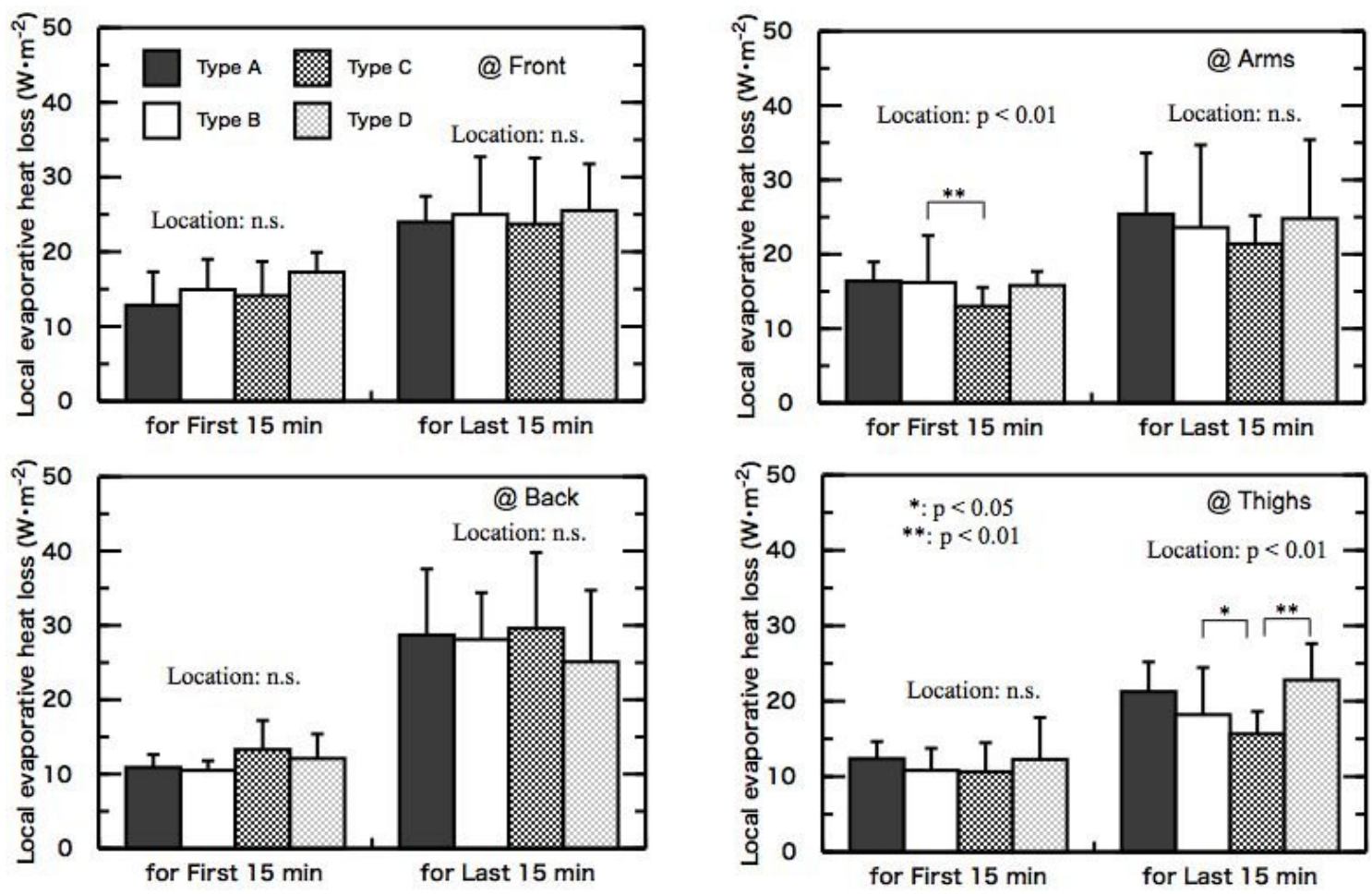

Figure 7 Calculated local evaporative heat loss from the target locations wearing the test garments of type A to D. 
Table 1 Specification of the employed test garments

\begin{tabular}{cccc}
\hline Type of garment & Target location & \multicolumn{2}{c}{ Covered area ratio (\%) with } \\
& & imp* & $\mathrm{p}^{*}$ \\
\hline Control & whole body** & 0.0 & 80.5 \\
Type A & chest and belly & 16.0 & 64.5 \\
Type B & back and buttock & 17.0 & 63.5 \\
Type C & arms & 18.0 & 62.5 \\
Type D & thighs & 16.0 & 64.5 \\
\hline
\end{tabular}

* imp and p mean impermeable and permeable for water vapour, respectively

** whole body except head, face, hands, and feet 
Table 2 Obtained experimental data of the skin surface in the target locations during for the first and the last 15 min

\begin{tabular}{|c|c|c|c|c|c|c|c|c|c|c|c|c|c|}
\hline \multirow[b]{2}{*}{ Location } & \multirow[b]{2}{*}{ Type of garment } & \multicolumn{6}{|c|}{ First 15 min (Rest period) } & \multicolumn{6}{|c|}{ Last 15 min (Exercise period) } \\
\hline & & \multicolumn{2}{|c|}{$\begin{array}{c}\text { Temperature } \\
\left({ }^{\circ} \mathrm{C}\right)\end{array}$} & \multicolumn{2}{|l|}{$\begin{array}{l}\text { Water vapour } \\
\text { concetration } \\
\left(10^{-2} \mathrm{~kg} \cdot \mathrm{m}^{-3}\right)\end{array}$} & \multicolumn{2}{|c|}{$\begin{array}{c}\text { Skin wettedness } \\
\text { (n.d.) }\end{array}$} & \multicolumn{2}{|c|}{$\begin{array}{c}\text { Temperature } \\
\left({ }^{\circ} \mathrm{C}\right)\end{array}$} & \multicolumn{2}{|l|}{$\begin{array}{l}\text { Water vapour } \\
\text { concetration } \\
\left(10^{-2} \mathrm{~kg} \cdot \mathrm{m}^{-3}\right)\end{array}$} & \multicolumn{2}{|c|}{$\begin{array}{l}\text { Skin wettedness } \\
\text { (n.d.) }\end{array}$} \\
\hline \multirow{5}{*}{ Front } & Control & $31.1 \pm 0.8$ & \multirow{5}{*}{ n.s. } & $1.4 \pm 0.1$ & \multirow{5}{*}{ n.s. } & $0.19 \pm 0.05$ & \multirow{5}{*}{$* * *$} & $29.9 \pm 0.8$ & \multirow{5}{*}{ n.s. } & $1.7 \pm 0.2$ & \multirow{5}{*}{$* * *$} & $0.37 \pm 0.56$ & \multirow{5}{*}{$* * *$} \\
\hline & Type A & $31.5 \pm 1.0$ & & $1.5 \pm 0.2$ & & $0.24 \pm 0.08$ & & $29.6 \pm 1.1$ & & $2.1 \pm 0.2$ & & $0.56 \pm 0.10$ & \\
\hline & Type B & $30.9 \pm 0.7$ & & $1.5 \pm 0.2$ & & $0.20 \pm 0.06$ & & $29.6 \pm 1.0$ & & $1.8 \pm 0.3$ & & $0.38 \pm 0.11$ & \\
\hline & Type C & $30.9 \pm 1.3$ & & $1.4 \pm 0.2$ & & $0.18 \pm 0.06$ & & $29.2 \pm 1.6$ & & $1.7 \pm 0.3$ & & $0.35 \pm 0.12$ & \\
\hline & Type D & $30.6 \pm 0.4$ & & $1.4 \pm 0.1$ & & $0.19 \pm 0.03$ & & $29.4 \pm 0.8$ & & $1.7 \pm 0.2$ & & $0.33 \pm 0.08$ & \\
\hline \multirow{5}{*}{ Back } & Control & $29.7 \pm 0.9$ & \multirow{5}{*}{$* *$} & $1.4 \pm 0.2$ & \multirow{5}{*}{$* * *$} & $0.17 \pm 0.07$ & \multirow{5}{*}{$* * *$} & $28.3 \pm 0.7$ & \multirow{5}{*}{ n.s. } & $1.7 \pm 0.2$ & \multirow{5}{*}{$* * *$} & $0.38 \pm 0.08$ & \multirow{5}{*}{$* * *$} \\
\hline & Type A & $29.6 \pm 0.6$ & & $1.3 \pm 0.1$ & & $0.14 \pm 0.02$ & & $28.2 \pm 0.8$ & & $1.8 \pm 0.3$ & & $0.40 \pm 0.17$ & \\
\hline & Type B & $30.8 \pm 1.3$ & & $1.5 \pm 0.1$ & & $0.22 \pm 0.03$ & & $29.5 \pm 1.6$ & & $2.3 \pm 0.3$ & & $0.65 \pm 0.17$ & \\
\hline & Type C & $30.1 \pm 0.7$ & & $1.3 \pm 0.1$ & & $0.15 \pm 0.04$ & & $28.7 \pm 1.3$ & & $1.7 \pm 0.3$ & & $0.36 \pm 0.13$ & \\
\hline & Type D & $29.8 \pm 0.9$ & & $1.3 \pm 0.1$ & & $0.15 \pm 0.04$ & & $28.2 \pm 0.6$ & & $1.6 \pm 0.3$ & & $0.34 \pm 0.12$ & \\
\hline \multirow{5}{*}{ Arms } & Control & $30.6 \pm 1.2$ & \multirow{5}{*}{ n.s. } & $1.4 \pm 0.1$ & \multirow{5}{*}{$*$} & $0.19 \pm 0.03$ & \multirow{5}{*}{$*$} & $29.6 \pm 1.4$ & \multirow{5}{*}{ n.s. } & $1.6 \pm 0.3$ & \multirow{5}{*}{$*$} & $0.29 \pm 0.12$ & \multirow{5}{*}{$* *$} \\
\hline & Type A & $30.4 \pm 0.9$ & & $1.3 \pm 0.1$ & & $0.18 \pm 0.02$ & & $29.5 \pm 1.1$ & & $1.6 \pm 0.3$ & & $0.28 \pm 0.08$ & \\
\hline & Type B & $30.6 \pm 1.0$ & & $1.5 \pm 0.1$ & & $0.20 \pm 0.05$ & & $29.3 \pm 1.2$ & & $1.6 \pm 0.2$ & & $0.28 \pm 0.09$ & \\
\hline & Type C & $30.2 \pm 0.7$ & & $1.5 \pm 0.1$ & & $0.24 \pm 0.04$ & & $29.5 \pm 0.8$ & & $1.8 \pm 0.2$ & & $0.41 \pm 0.08$ & \\
\hline & Type D & $30.2 \pm 1.4$ & & $1.3 \pm 0.1$ & & $0.18 \pm 0.02$ & & $29.5 \pm 1.3$ & & $1.6 \pm 0.3$ & & $0.28 \pm 0.12$ & \\
\hline & Control & $29.5 \pm 0.8$ & & $1.3 \pm 0.1$ & & $0.16 \pm 0.04$ & & $29.4 \pm 1.2$ & & $1.5 \pm 0.1$ & & $0.28 \pm 0.06$ & \\
\hline & Type A & $29.3 \pm 1.0$ & & $1.3 \pm 0.1$ & & $0.15 \pm 0.02$ & & $28.6 \pm 0.9$ & & $1.5 \pm 0.1$ & & $0.29 \pm 0.05$ & \\
\hline Thighs & Type B & $29.4 \pm 0.8$ & n.s. & $1.4 \pm 0.1$ & $* *$ & $0.16 \pm 0.04$ & $* * *$ & $29.3 \pm 1.1$ & $*$ & $1.6 \pm 0.2$ & $* * *$ & $0.29 \pm 0.08$ & $* * *$ \\
\hline & Type C & $29.8 \pm 1.5$ & & $1.3 \pm 0.1$ & & $0.16 \pm 0.04$ & & $29.3 \pm 1.1$ & & $1.5 \pm 0.1$ & & $0.26 \pm 0.05$ & \\
\hline & Type D & $29.8 \pm 1.4$ & & $1.5 \pm 0.2$ & & $0.25 \pm 0.08$ & & $29.8 \pm 0.9$ & & $2.0 \pm 0.2$ & & $0.50 \pm 0.11$ & \\
\hline
\end{tabular}

In the table, the shaded area shows the target zone covered with the impermeable material.

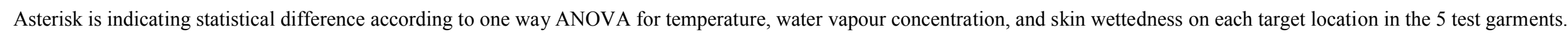

Numbers of the asterisk show level of the significance; ***: $p<0.001, * *: p<0.01, *$ : $p<0.05$, n.s.: no siginificance. 
Table 3 Correlation coefficients between thermal comfort sensation in the whole body and skin surface temperature and skin wettedness in the individual target location.

\begin{tabular}{|c|c|c|c|c|c|c|c|c|c|c|}
\hline \multirow[b]{3}{*}{ Skin surface temperature } & \multirow{2}{*}{\multicolumn{2}{|c|}{ Whole body }} & \multicolumn{8}{|c|}{ Individual target location } \\
\hline & & & \multicolumn{2}{|c|}{ Front } & \multicolumn{2}{|c|}{ Back } & \multicolumn{2}{|c|}{ Arms } & \multicolumn{2}{|c|}{ Thighs } \\
\hline & 0.204 & $\mathrm{p}<0.0001$ & -0.312 & $\begin{array}{c}\text { n.s. } \\
(p=0.461)\end{array}$ & 0.250 & $\mathrm{p}<0.0001$ & -0.406 & $\mathrm{p}<0.001$ & -0.003 & $\begin{array}{c}\text { n.s. } \\
(p=0.937)\end{array}$ \\
\hline Skin wettedness & -0.433 & $\mathrm{p}<0.001$ & -0.347 & $\mathrm{p}<0.0001$ & -0.365 & $\mathrm{p}<0.001$ & -0.381 & $\mathrm{p}<0.001$ & -0.324 & $\mathrm{p}<0.0001$ \\
\hline
\end{tabular}


Table 4 Correlation coefficients between local thermal comfort sensation and its temperature and wettedness of the skin surface in the individual target location

\begin{tabular}{|c|c|c|c|c|c|c|c|c|}
\hline \multirow[b]{3}{*}{ Local skin surface temperature } & \multicolumn{8}{|c|}{ Individual location } \\
\hline & \multicolumn{2}{|c|}{ Front } & \multicolumn{2}{|c|}{ Back } & \multicolumn{2}{|c|}{ Arms } & \multicolumn{2}{|c|}{ Thighs } \\
\hline & -0.149 & $\begin{array}{c}\text { n.s. } \\
(p=0.724)\end{array}$ & 0.268 & $\mathrm{p}<0.0001$ & -0.435 & $\mathrm{p}<0.0001$ & 0.019 & $\begin{array}{c}\text { n.s. } \\
(p=0.664)\end{array}$ \\
\hline Local skin wettedness & -0.375 & $\mathrm{p}<0.0001$ & -0.336 & $\mathrm{p}<0.0001$ & -0.360 & $\mathrm{p}<0.0001$ & -0.357 & $\mathrm{p}<0.0001$ \\
\hline
\end{tabular}

